\title{
Adelaide Miranda e Pedro Chambel (coord.), Bestiário Medieval. Perspectivas de Abordagens
}

Maria Eurydice de Barros Ribeiro

\section{(2) OpenEdition}

1 Journals

\section{Edição electrónica}

URL: http://journals.openedition.org/medievalista/1142

DOI: 10.4000/medievalista. 1142

ISSN: 1646-740X

\section{Editora}

Instituto de Estudos Medievais - FCSH-UNL

\section{Refêrencia eletrónica}

Maria Eurydice de Barros Ribeiro, « Adelaide Miranda e Pedro Chambel (coord.), Bestiário Medieval. Perspectivas de Abordagens », Medievalista [Online], 18 | 2015, posto online no dia 01 junho 2015, consultado o 23 setembro 2020. URL : http://journals.openedition.org/medievalista/1142 ; DOI : https://doi.org/10.4000/medievalista.1142

\section{(c) $(1)(9$}

Mediavalista está licenciado com uma Licença Creative Commons - Atribuição-NãoComercial 4.0 Internacional 
Título: Recensão: MIRANDA, Adelaide; CHAMBEL, Pedro (coord.) - Bestiário Medieval. Perspectivas de Abordagens. Lisboa: Instituto de Estudos Medievais, 2014. E-book (110 p.). ISBN: 978-989-987-3-0 [disponível em http://iem.fcsh.unl.pt/ebooks/estudos10/index.html] Autor: Maria Eurydice de Barros Ribeiro Universidade: Universidade de Brasília Faculdade e Departamento / Unidade de Investigação: Departamento de História / UnB. Código Postal: 70910900

Cidade: Brasília, DF

País: Brasil

Contacto: maycebarros@gmail.com

Fonte: Medievalista [Em linha]. Direc. José Mattoso. Lisboa: IEM.

Disponível em:

http://www2.fcsh.unl.pt/iem/medievalista/MEDIEVALISTA18/ribeiro1810.html

ISSN: 1646-740X

Data do texto: 5 de Abril de 2015 


\section{Recensão}

MIRANDA, Adelaide; CHAMBEL, Pedro (coord.) - Bestiário Medieval. Perspectivas de Abordagens. Lisboa: Instituto de Estudos Medievais, 2014. E-book (110 p.). ISBN: 978-989-987-3-0

[disponível em http://iem.fcsh.unl.pt/ebooks/estudos10/index.html].

\section{Maria Eurydice de Barros Ribeiro}

Vivemos em uma sociedade onde os animais, pode-se dizer, passaram a fazer "parte da família”. Boa parte das famílias, quer na Europa ou nas Américas, possuem um cão, um gato, um pássaro, um coelho, uma tartaruga ou um peixe. Há mesmo aqueles que adotam animais nem sempre considerados como domésticos, tais como porcos, aves de rapina, cobras e toda uma variedade de répteis. A nossa intimidade com os animais é tamanha, que já gerou filmes e livros comoventes, personagens de desenhos animados e até mesmo mais de um canal de televisão são exclusividade dos animais. Trata-se aí, não só das suas doenças e particularidades, mais até da sua estética, buscando humanizá-los com vestimentas femininas ou masculinas. Este é um mercado que em muitos países movimenta milhões. A relação homem/animal é tão antiga quanto a existência dos homens e dos animais. Em tempos remotos, os homens não só se nutriram dos animais, como chegaram a vestir, literalmente, a sua pele.

Todavia, Michel Pastoureau, sem dúvida uma autoridade da história dos animais, afirma que em nenhuma outra época no Ocidente o animal esteve tão presente no pensamento, nas narrativas e nas variadas representações como na Idade Média. Segundo ele, "Les animaux abondent jusque dans les églises, où ils constituent une bonne part du décor et 
de l'horizon figuré - peint ou sculpté - que les prêtres, les moines et les fidèles ont quotidiennement sous les yeux". ${ }^{1}$ Presentes por toda parte, dos capitéis às fachadas exteriores, do interior dos manuscritos às tapeçarias que cobrem as paredes, os animais porém, permaneciam ignorados pelos historiadores. Pastoureau lembra das imensas dificuldades que nos finais dos anos 60, ele encontrou quando decidiu escolher, como tema de tese na École des Chartes (Paris), o bestiário heráldico medieval.

Desde então, muita coisa mudou e o animal, nas suas palavras, se tornou "um objeto por inteiro dos historiadores”. ${ }^{2}$ Porém, é importante sublinhar que, desde o início do século $\mathrm{XX}$, alguns "passos decisivos abriram caminho para os trabalhos especializados que surgiram depois. No XV Encontro da Sociedade Internacional Renardienne em Louvain-la-Neuve (2003), os organizadores decidiram eleger o bestiário como tema principal. As comunicações selecionadas foram publicadas e, no final do volume, Baudouin Van Den Abeele $^{3}$ deu continuidade à conhecida bibliografia organizada por W.B. Clark e M.Mc Munn no volume coletivo Beasts and Birds of Middle Ages. The Bestiary and its Legacy (1989) que, por sua vez, retomava os títulos levantados a partir de 1962, aquando da última edição de Florence McCulloch, Medieval Latin and French Bestiaires. Van Den Abeele atualizou a bibliografia, acrescentando os trabalhos publicados nos últimos quinze anos.

Ora, mais que oportuno, é muito bem-vinda a iniciativa do grupo de investigação Dicionário de Simbologias Animais que está se propondo a efetuar um "levantamento exaustivo das representações textuais e figurativas dos animais nas fontes medievais portuguesas”. Este, sem dúvida, será de grande utilidade aos medievalistas que se interessam pela história dos animais na Idade Média. O grupo tem a intenção de constituir "uma base de dados online onde os animais estarão contextualizados nas fontes onde surgem referenciados e com atribuições simbólicas propostas pelos membros do grupo”. Bestiário Medieval, Perspectivas de Abordagens, publicação

\footnotetext{
${ }^{1}$ PASTOUREAU, Michel - "L'historien face à l'animal: l'exemple du Moyen Age”. in BIRNBAUM, Jean (Direction). Qui sont les animaux? Paris: Ed. Gallimard, 2010, p. 194. ISBN 978-2-07-043827-3

${ }^{2}$ Ibidem.

${ }^{3}$ VAN DEN ABEELE, Baudouin - Bestiaires Médiévaux. Nouvelles Perspectives sur les Manuscrits et les Traditions Textuelles. Louvain-la-neuve: Brepols Publishers, 2005, pp 283-300. ISBN 13:9872503519838
}

Medievalista online № 18| Julho - Dezembro 2015 ๑ IEM - Instituto de Estudos Medievais 3 www2.fcsh.unl.pt/iem/medievalista 
online realizada em 2014, reúne trabalhos dos pesquisadores do grupo que, reunidos no seminário sobre a temática das representações animais na Idade Média, pretendem divulgar a pesquisa do grupo promovendo um amplo debate sobre as questões próprias aos animais. A abertura é feita pela Apresentação do Projeto de Investigação “Dicionário de Simbologias Animais”. Problemática, Questões e Orientações, por Pedro Chambel, que reafirma os propósitos do grupo de investigação e do dicionário serem voltados para Portugal, o que possibilitará aos demais medievalistas um instrumento inestimável. Tal ferramenta será capaz de favorecer a análise crítica das fontes textuais e figurativas do medievo português. O período contemplado estende-se do século XII ao século XV. Pedro Chambel é cuidadoso ao sugerir as abordagens para o estudo da simbólica em Portugal, chamando a atenção para a definição do símbolo, “que é composto por um significante” (o animal) e por um significado, que "remete para o indizível, o inacessível e para a transcendência”. Insistindo, mais adiante, na importância do contexto em que o animal é referenciado, ao pesquisador não escapa também, a importância do suporte, do lugar e da região produtora da fonte. E, finalmente, reconhece que o estudo das simbologias animais exige um tratamento multidisciplinar e mesmo transnacional. Lembre-se, aqui, que os mosteiros portugueses não foram produtores de textos, mas sobretudo reprodutores, donde a importância da origem da fonte e da sua datação. O estudo da iluminura em Portugal avançou consideravelmente, graças à Prof. Adelaide Miranda e a sua equipe, mas, certamente, ainda há o que fazer.

Finalmente, o recorte temporal é perfeito: $\mathrm{O}$ autor se atém às importantes mudanças operadas no universo medieval a partir dos finais do século XII e principalmente, no XIII, graças ao papel decisivo da leitura dos textos de Aristóteles. Como se sabe, a escolástica, dentre as modificações importantes que inseriu no ambiente monástico, operou nos bestiários, introduzindo novos animais, como no caso das aves de rapina, conforme indica Réau ${ }^{4}$. A escolha do século XV como baliza entre os dois momentos aponta corretamente para a continuidade das crenças medievais que impregnaram o olhar dos primeiros navegadores portugueses.

\footnotetext{
${ }^{4}$ RÉAU, Louis - Iconographie de l'art chrétienne. Paris: PUF, 1955-59, p. 74.
} 
O seminário contou com seis comunicações, que possuem qualidade acadêmica e revelam o desenvolvimento de uma pesquisa que leva em consideração os parâmetros sólidos indicados por Chambel.

1. Margarida Mafra nos revela em Animália a simbólica do bestiário um trabalho precioso, onde expõe passo a passo como surgiu a ideia no grupo de trabalho Imagens Medievais de criar Uma base de dados dedicada à representação do Bestiário nas artes portuguesas dos séculos XII-XV e como aos campos escolhidos inicialmente (Literatura, Escultura e Iluminura) foi acrescentada atualmente a Ourivesaria. Com precisão, Mafra descreve as primeiras fichas ainda não introduzidas online. "Cada área de pesquisa possui um formato diferente, espécie de bilhete de identidade, dedicada a cada representação de animal”. Com relação à iluminura, foram introduzidas 107 fichas, correspondentes aos manuscritos portugueses dos três Livros das Aves (séculos XII e XIII) e ao Livro das Horas de D. Leonor (séc. XV). A configuração geral da ficha, além das informações indispensáveis à identificação do animal, acrescenta a fonte, a cota, o fólio e a data. Pormenorizando a análise, busca identificar a discrição, simbologia, suporte, dimensões, imagem, instituição produtora e detentora do manuscrito e as referências bibliográficas úteis na análise do animal representado, conforme colocado anteriormente, por Pedro Chambel. Da escultura possui-se 38 fichas, todas do século XIII. Estas fichas, por razões óbvias, diferem das anteriores relativas às iluminuras. Da literatura constam 23 fichas, relativas a 6 manuscritos datados dos séculos XIV e XV. Na estrutura destas fichas substituíram-se as Cotas pelos campos Edição e Página bem como Imagem pelo Enxerto Ilustrativo retirado da fonte. Os demais campos, exceção ao das dimensões, foram mantidos. Dois aspectos me parecem bastante interessantes na comunicação de Margarida Mafra, o primeiro é a sintonia perfeita em relação a comunicação anterior, deixando a perceber a interação com o grupo, o segundo é o título Animalia, que de acordo com a tradução do latim, define de forma clara a base de dados. Torna-a mais ampla e aberta a toda a literatura medieval sobre os animais, e não apenas aos bestiários, cuja significação no medievo parece-me mais restrita. 
2. É de Ingrid Matschinegg a próxima comunicação intitulada Localising Animals in Late Medieval Visual Art. Animals Shown at Images from the Digital Image-Server REALonline. ${ }^{5}$ A autora apresenta o arquivo fotográfico de imagens sobre o patrimônio visual da Idade Média e início da Modernidade que o Instituto de Cultura Material afiliado à Academia Austríaca de Ciências possui. A coleção contém atualmente uma média de 20.000 objetos provenientes, de modo geral, da Europa ocidental e central, abarcando os anos de 1200 a 1650.

O projeto teve início na década de 1970 e desde então garante a digitalização de todos os objetos adquiridos pelo Instituto, criando um banco de dados que, além das imagens, contém descrições dos objetos. Este trabalho permite a aproximação com a cultura material, bem como com o cotidiano e com as concepções ideológicas e simbólicas na Idade Média.

A contribuição maior para o que interessa ao Projeto Dicionário de Simbologias Animais é que no arquivo fotográfico os animais aparecem nas mais variadas formas de manifestação artística, destacando-se a produção dos bestiários e outros manuscritos provindos do Fisiólogo, ou mesmo outras produções como a própria Bíblia. O arquivo permite visualizar o papel que os animais possuíam na cultura medieval, tanto para a vida cotidiana, quanto para a propagação de conteúdos simbólicos cristãos.

O instituto realizou um mapeamento do aparecimento dos animais nas imagens de seu acervo, chegando a uma divisão em 250 categorias. Note-se aqui que o termo “animais” tem um conceito amplo ao tratar-se de Idade Média, sendo necessário considerar tanto os animais fabulosos e criaturas míticas, quanto os animais do mundo natural.

Dentre eles, os três animais mais frequentes são: o cavalo, o cachorro e o dragão. A partir de breves considerações a respeito da simbologia desses animais e de outros, mais frequentes, como o boi, o burro, a águia, o leão, o cordeiro e a cobra - no contexto teológico - bem como do gato na cultura popular, demonstra-se que o banco de dados do Instituto serve como importante ferramenta de busca para pesquisas a respeito da cultura material da Idade Média e início da Modernidade. Esse acervo é de domínio

\footnotetext{
5 Agradecemos a colaboração de Sara Scholze, aluna do Programa de Pós-graduação em Artes (mestrado), da Universidade de Brasília-UnB, Brasília, DF.
}

Medievalista online № 18| Julho - Dezembro 2015 ๑ IEM - Instituto de Estudos Medievais 6 www2.fcsh.unl.pt/iem/medievalista 
público e está disponível no endereço eletrônico: www.imareal.oeaw.ac.at/realonline, sob o servidor REALonline.

3. O Bestiário. Um Gênero Medieval é abordado por Angélica Varandas. A comunicação retoma o aparecimento, no século XII, na Inglaterra e na França, dos primeiros escritos que passaram a ser nomeados de Bestiários, por Pierre de Beauvais. Varandas aponta a tradição grega do texto que tem como ponto de partida o Fisiólogo, indicando as fontes que fundamentam o mesmo. Em seguida, ela busca referência no manuscrito grego (desaparecido) que se encontra na base das traduções latinas. Valorizando os trabalhos realizados pelos críticos, cujo empenho resultou na classificação das famílias dos manuscritos ingleses, a autora distingue nas quatro famílias propostas por James, a segunda, na qual inclui “os manuscritos mais representativos dos séculos XII a XIV. Ela conclui com firmeza que estes “distinguemse das versões do Fisiólogo e dos textos da terceira e quarta famílias por possuírem características comuns”.

Os manuscritos da segunda família, acrescenta, são todos de origem inglesa. Definindo o bestiário como "um texto didático que encontrando na Bíblia o reduto singular de ensinamentos morais e religiosos se destina a veicular verdades de ordem teológica àqueles a quem se destina: noviços e conversos das ordens religiosas que o utilizam como livro de estudo”. No Bestiário, prossegue, a leitura se processa “da naturas para a figuras,” que domina e se impõe à parte descritiva, determinando os limites da interpretação dos símbolos animais. Cada animal é um exemplum, permitindo que no bestiário seja permitida a passagem do literal ao alegórico e deste ao místico ou anagógico. Distingue claramente a presença do neoplatonismo cristão, que se fez presente no mundo medieval até os finais do século XIII e início do XIV, momento em que o mundo passará por mudanças significativas.

Um dos méritos de Angélica Varandas é a capacidade de avaliar de forma equitativa as relações entre texto e figura. Assim, buscou datar os primeiros manuscritos iluminados de cerca de 1180. Situando a usual representação do animal em cada capítulo, ela referese à variedade dos tamanhos e às imagens narrativas que, às vezes, invocam cenários tanto do campo, quanto da cidade. Enfatiza que todas as imagens "percorrem as mesmas 
etapas que o texto escrito e, tal com este, pressupõem que a literalidade da figura seja abandonada em prol da sua componente alegórica”. A autora sinaliza como, em particular, os manuscritos ingleses da segunda família estão preocupados com o ciclo da criação, baseado no Génesis, dando como exemplo Aberdeen e Ashmole, influenciados pelo Hexameron de Santo Ambrósio. Por isso, segundo ela, não causa surpresa nestes manuscritos as ilustrações de Adão.

É de grande interesse a tabela Histograma relativa à circulação dos bestiários produzidos na Inglaterra no decorrer da Idade Média, pois permite visualizar a produção dos manuscritos no tempo - o momento de pico é o século XIII - para em seguida perceber o decréscimo a partir do século XIV até praticamente desaparecer no século XV. O interesse da tabela está no facto de nos fazer ver uma informação que tínhamos mas que não víamos. Assim, percebe-se a eficiência que uma imagem, independente do seu conteúdo, produz ainda hoje. Vê-se que foi no medievo que o Bestiário apareceu, cresceu, alcançou o seu ponto máximo e entrou em decadência, desaparecendo. Segundo Varandas, dentre as razões deste percurso, destaca-se o próprio homem medieval, que recorreu à temática animal para discorrer sobre as virtudes e os vícios. Revela-se assim, o desejo humano de se aproximar do Redentor e garantir a salvação.

4. Ana Paiva Morais se propõe a examinar a produção crítica sobre a literatura de animais na narrativa curta medieval, estabelecendo um breve estado da questão no texto Sobre os Animais na Matéria das Fábulas Medievais: O Livro de Exopo. Para ela, o texto nasceu da perplexidade provocada pela escassez de estudos relativos ao panorama da crítica às fábulas medievais. Fazendo uma breve revisão historiográfica, ela se refere à raridade dos trabalhos que tratam da problemática dos animais enquanto matéria da fábula. A autora reconhece a introdução dos animais na literatura medieval por aqueles que estudam os exempla e o bestiário. Porém, acrescenta "no que à fábula medieval diz respeito, o que salta a vista é uma falta de curiosidade pelos animais como matéria privilegiada, ou melhor dizendo, a ausência de uma interrogação crítica sobre o assunto.” A sua afirmativa é ilustrada pela referência aos trabalhos realizados no grupo de Antropologia Histórica do Ocidente Medieval (GAHOM/EHESS/Paris) e aos trabalhos mais recentes de Gert-Jan Van DijK e Hugo O. Bizarri. 
Particularizando os animais no Livro de Exopo, única coleção de fábulas medievais em língua vulgar portuguesa de que se tem notícia, conservada na Biblioteca Palatina de Viena (ms.3270), datada provavelmente do século XV e conhecida recentemente, graças a Leite de Vasconcelos, Paiva Morais refere ainda a existência de mais duas transcrições do fabulário português. Seleciona a transcrição de autoria de Adelino de Almeida Calado, Livro de Exopo, por ser "aquela que mais fielmente respeita a letra do texto editado.” Descreve o conteúdo do texto formado de 63 fábulas, e insiste na representação dos animais, citando o trabalho de Michel Zink (1984). Para a autora, embora aí também o lugar reservado a fábula seja de pouca relevância, Zink, no capítulo que denomina animais portadores de sentido, confere à fábula uma dimensão particular, na medida em que é o único gênero que não está associado nem à alegoria, nem à exegese. As fábulas definem-se pela sua moralidade mas, diferente dos bestiários de “significação imutável”, “a anedota particular põe em evidência um tipo de comportamento que a moralidade convida a transpor do mundo animal para o mundo humano, transposição esta em que o jogo da analogia e da distância entre o animal e o homem contribui para suscitar o interesse e tornar convincente.”

Sem se deter no prólogo das Fábulas e em outras questões, Morais declara o propósito da comunicação, que pretende compreender "de que maneira os protagonistas animais poderão, melhor ou mais do que outros, contribuir para aprofundar o mecanismo da analogia num contexto da literatura didática, isto é, perceber qual é a eficácia desta matéria.” Em seguida, recorre ao exemplo da literatura de exempla, afirmando que a estrutura das fábulas no Livro de Exopo é simples. Cita a fábula “O Lobo e a grua”, concluindo com a sentença que resume a lição: A emgratidõe sseca a fonte da piedade. Fica claro que não existe dúvida quanto ao caráter exemplar da fábula, que, inclusive, repete em todas as fábulas da coleção a fórmula "por este exemplo”. A autora observa que “o narrador distingue "exemplo” de "hestória," narrativa enquanto tal, ao passo que “exemplo” indica a narrativa moralizada ou enquadrada num horizonte didático e de moralização”. Prosseguindo no contexto da literatura exemplar, faz referência a um dos mais importantes repositários de exempla do século XIII, os Sermones Vulgares de Jacques de Vitry. O franciscano utilizava na pregação uma pedagogia sistematicamente orientada no sentido de proporcionar uma experiência sensorial, em particular a visão. Concluindo, os animais adequam-se “à função exemplar da narrativa de uma maneira 
muito significativa, sobretudo naquilo que respeita ao exemplum vivendi, no qual é sublinhada a transferência para o presente das verdades que se procura transmitir, a sua experiência empírica, ou seja uma exemplaridade inscrita na vida”.

Concluindo, Ana Paiva Morais analisa uma outra contribuição para o esclarecimento da problemática dos animais nas fábulas esópicas. Trata-se de um artigo publicado no anuário da Société Internationale Renardienne sobre a alegoria secular. O autor, Haijo J. Westra, refere-se ao que nomeia “interpretação múltipla”, isto é “a possibilidade de interpretar uma mesma figura mitológica como símbolo do pensamento e da significação em situações diversas, sendo Proteu a figura exemplar dessa multiplicidade”. Para Westra fica claro que a fábula é capaz de "inverter o seu próprio jogo" isto é que "a multiplicidade que à partida se apresenta como negativa, adquira qualidades positivas.”

Enfim, nesta instigante comunicação, a autora demostra com sensibilidade a necessidade que o projeto deve "fazer uma comparação de materiais de várias coleções em língua vulgar, em conjugação com um exame das discussões acerca da utilização de fontes profanas em vários contextos entre os séculos XII e XV.

5. Sobreviveram cerca de setenta tímpanos do período Românico em Portugal, afirma Patrícia Lopes em As Representações de Bestiário nos Tímpanos das Igrejas Românicas (Século XIII). Ao mesmo tempo, ela aponta a dificuldade de uma abordagem iconográfica destes tímpanos, devido ao estado de degradação provocado pelo tempo, ou pelo Homem. Lopes selecionou vinte e seis tímpanos românicos do século XIII. Dentro do contexto artístico e religioso da época, aos tímpanos estavam reservados os motivos de maior importância iconográfica. Segundo a autora, "a escultura românica portuguesa afasta-se das obras francesas ou espanholas, tanto do ponto de vista plástico como iconográfico. Ela é o testemunho do gosto e do vocabulário plástico medieval português”. Os tímpanos são ornamentados tanto por bestas aladas, quanto míticas, quadrúpedes, aves e anfíbios. Tais representações são feitas tanto isoladas, quanto integrando uma composição vinculada à Árvore da Vida, ou acompanhando a Cruz, ou estando associada a atributos de santos. Com relação aos animais, eles se originam do bestiário, que incorporou também animais fantásticos, tais como o dragão, o grifo e a 
harpia. Dentre todos os animais, o cordeiro predomina, afirma a autora. Ele é exibido em doze tímpanos, seguido da representação do leão (seis representações em cinco tímpanos), do dragão (quatro vezes em três tímpanos) da serpente três vezes, da águia e das aves de espécie indefinida duas vezes; enquanto o cavalo, o touro, a pomba e os míticos grifo e harpia estão representados em um único tímpano.

Destacando que a simbologia dos animais pode variar de acordo com o contexto, Lopes afirma que o cordeiro em todas as obras analisadas "assume-se como o Cordeiro de Deus ou Agnus Dei”. Independente da sua função apocalíptica, o objetivo da representação é sempre o cordeiro. No caso da forma apocalíptica, a fonte é o Apocalipse de João. Em seguida, os animais têm a sua função simbólica revelada a partir do local onde se encontram, como a pomba (portal ocidental da capela de Santo Abdão) associada à alma, considerando que esta capela tinha função funerária, ou como o grifo, que no portal lateral norte da igreja de São Cristóvão de Rio Mau, personifica as forças do Bem. Todavia, Patrícia Lopes adverte que existem animais cuja função simbólica varia de acordo com o contexto da representação, tal como a águia e o leão. Acrescenta ainda que existem animais que podem assumir "uma conotação negativa ou positiva de acordo com o contexto da representação em que estão inseridos”. Foram identificadas duas bestas que preenchem estes requisitos: a serpente e o dragão.

Patrícia teve o cuidado de expor os dados em três tabelas que facilitam a compreensão do leitor. Em uma certa medida, na tabela 3, ela antecipa uma parte do Dicionário, propondo duas categorias aos animais: a simbologia e o local onde se encontram. Ora percebe-se assim, em um lance do olhar, de que animal se trata, o que ele simboliza e onde ele está (que é o identificador do seu valor simbólico).

\section{6. É com o Bestiário Fantástico das Águas. Evolução do Legado da Antiguidade na} Época Medieval, que Cátia Mourão encerra a série de comunicações publicadas. Ela inicia invocando a vastidão, diversidade, prodigalidade e utilidade do meio aquático, que tocou o homem, colocando-o entre "a realidade e a fantasia, o temor e o fascínio, a objetividade científica e a subjetividade mística”. Tomando como ponto de partida os povos mediterrânicos da Antiguidade, responsáveis por "uma imensa plêiade de deidades marinhas e fluviais, fontenárias, a quem cultuavam para garantirem a 
afirmação política dos seus soberanos e a prosperidade socioeconômica das suas potências talassocráticas”, a autora afirma que muitas das criaturas que integraram o bestiário aquático da Antiguidade, assim como algumas de suas estórias morais, "sobreviveram além do tempo e do contexto religioso em que surgiram, conformandose a uma mundividência cristã e incorporando o bestiário medieval”. Mourão identifica três categorias na classificação das criaturas: o bestiário puro mitificado, o bestiário teratológico mítico e o bestiário híbrido mitológico. A primeira categoria agrega as criaturas aquáticas oriundas do paganismo greco-romano e acolhidas pelo cristianismo, tais como o peixe, o golfinho, os biveres e o coral, "todos eles considerados outrora, como agora, animais divinos e benéficos.” A autora se dedica à análise de cada categoria, caracterizando as criaturas. Na primeira categoria, refere-se ao peixe, apreciando desde o valor gastronômico, emblemático, atributo de divindades marinhas até a manutenção do seu caráter divino pelo cristianismo associado ao Filho de Deus. "No contexto cristão, a preferência pela forma ictiográfica simplificada sobre a especificada, denunciava não apenas a constituição do peixe como emblema do Cristo, mas também a valorização da dimensão simbólica da imagem ictiográfica em detrimento da dimensão concreta do animal aquático.” Segue-se nesta categoria, com análise qualitativa semelhante, o golfinho (que embora mamífero, era considerado como peixe na Antiguidade), os bivalves e o coral. Na categoria seguinte - bestiário aquático teratológico mítico - trata-se das criaturas que, mesmo mitificadas e acrescidas de sentidos simbólicos fantasiosos, caracterizam-se pela exceção à norma física. Cabem aí os monstros teratológicos pagãos, que raramente sobreviveram na Idade Média, tendo cedido lugar a outros. Apesar das diferenças morfológicas, os monstros "conservaram o princípio de equivalência entre a desproporção, a deformação e a imoralidade”. Apesar das dificuldades em estabelecer qualquer relação contextual direta, Cátia Mourão selecionou o caranguejo gigante, contextualizando-o na tradição clássica (destaca-se em um dos doze Trabalhos de Héracles) e no contexto cristão, onde aparece raramente, figurado “como excelso emblema da invulnerabilidade de Cristo, em virtude da sua rija carapaça”. Finalmente, na terceira categoria, a autora destaca o bestiário aquático híbrido mitológico, descrevendo tais criaturas como pertencentes a duas ou mais espécies diversas. Vários seres híbridos do paganismo greco-romano prosperaram no cristianismo, tais como a Hidra de Lerna, os bodes-marinhos, os cotoi e as sereias. Tais seres habitavam os rios e os mares. Finalmente, Mourão conclui que “o bestiário 
fantástico das águas tinha (e em alguns casos mantém) um enorme potencial alegórico e didático, funcionando como poderoso auxiliar na formação cultural moral e cívica, primeiro do Homem Romano pagão e dos povos conquistados e depois do Homem Medieval cristão.

Embora o projeto tenha como baliza o século XV, não é possível deixar de reconhecer a continuidade do bestiário medieval português transladado para o Brasil. Seja com a sereia, cujo processo complexo de sincretismos com a cultura negra e a cultura indígena associou-a a bela Iemanjá, a Mãe d‘água, a Janaína (no mar) ou a Yara nos rios. Todas cultuadas festivamente, ainda hoje. Ou, na variedade do cordel nordestino, onde a serpente e a pomba, mantendo o mesmo simbolismo dos bestiários medievais, transformaram a caatinga do nordeste no deserto de tentações do romeiro.

Concluindo, pergunto-me: Até que ponto na história do Império Português, animais reais ou imaginários, emigraram para terras do além-mar mantendo a mesma forma, ou se metamorfoseando em novos animais?

\section{COMO CITAR ESTE ARTIGO}

\section{Referência electrónica:}

RIBEIRO, Maria Eurydice de Barros - "Recensão: MIRANDA, Adelaide ; CHAMBEL, Pedro (coord.) - Bestiário Medieval. Perspectivas de Abordagens. Lisboa: Instituto de Estudos Medievais, 2014. E-book (110 p.). ISBN: 978-989-987-3-0 [disponível em http://iem.fcsh.unl.pt/ebooks/estudos10/index.html]”. Medievalista [Em linha]. No 18 (Julho - Dezembro 2015). [Consultado dd.mm.aaaa]. Disponível em http://www2.fcsh.unl.pt/iem/medievalista/MEDIEVALISTA18/ribeiro1810.html ISSN 1646-740X. 


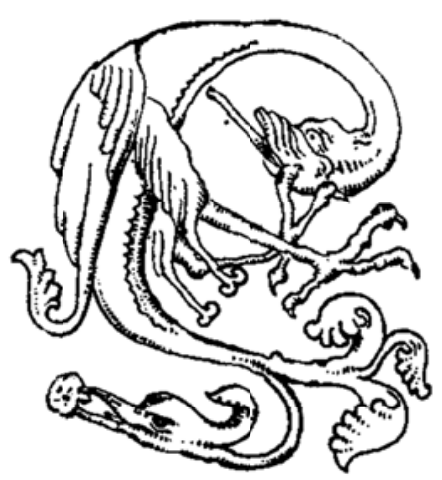

